\title{
Health literacy and harm: Who is at risk? What is the fix?
}

\author{
Allan Frankel MD \\ $\infty$ \\ See related article page 1555
}

$\mathrm{T}$ he study by Bartlett and colleagues ${ }^{1}$ on the risk of preventable adverse events among patients with communication problems admitted to acute care hospitals in this issue of $C M A J$ highlights major known flaws in how health care is delivered. It also reminds us of 2 types of needed improvements in health care: those that are simple but hard to do, and those that are complex and disruptive.

The authors chose to focus on patients with communication problems, but they also have shone a broader light on the risks to all patients. The results of this study revealed that some patients' communication problems predisposed them to a 3 -fold increased risk of a preventable adverse event and identified a segment of the patient population worthy of extra scrutiny and effort. The results also revealed the ubiquity of error and the universality of risk, whether inpatient or outpatient, preadmission or postadmission. It comes as little surprise that elderly women, those who were admitted to hospital because of an emergency and those whose ability to communicate with health care providers was limited because of a foreign language, deafness or a psychiatric disorder were the patients most likely to receive inadequate care. This constellation of characteristics requires a health care system whose very fabric has woven into it patience and cultural sensitivity, which is not exactly a picture of current generalcare or emergency-response systems in most health care systems worldwide. ${ }^{2}$

Deafness adds an extraordinary level of complexity to the care process. In addition to data suggesting that less than $20 \%$ of deaf individuals are fluent in reading English, nuanced differences exist between English and American Sign Language and may lead to substantial misunderstanding. ${ }^{3}$

The 2 main factors associated with preventable adverse events in the study by Bartlett and colleagues were communication problems and poor clinical management. If we start with communication, a national study in the United States indicated that one-third of individuals have below basic or basic reading skills. ${ }^{4}$ Individuals with such reading skills are unlikely to understand more than the simplest written documents or verbal explanations. Health care providers, who tend to write and speak at a graduate level, get little training or organizational support about how to bridge this comprehension chasm. As a result, medical documents are often written at a roth-grade level or higher, and verbal communications are fraught with opportunities for misunderstanding. ${ }^{5}$

In a video produced by the American Medical Association to highlight issues of patient health literacy, one segment

\section{Key points}

- All patients are at risk of preventable adverse events, regardless of disabilities or communication limitations.

- Common factors that lead to harm are communication and poor clinical management.

- Simple mechanisms to enhance patient comprehension are well known, but must be vigorously applied.

- Decreasing the risk of preventable adverse events will also require effective standardization and simplification of care.

shows a female physician discussing the word "hypertension" with a gentle and calm elderly male patient. The physician asks the patient what he understands when she says hypertension. The elderly man, sitting quietly in his chair, replies that he thinks the physician perceives him as hyperactive and unable to sit still in his chair. The physician then replies that she has not done an effective job of explaining his medical problem and that his problem is not hyperactivity but high blood pressure. ${ }^{6}$

A solution is to implement a framework of communication that ensures patients know the steps needed to take care of themselves. Work promulgated through the Partnership for Clear Health Communication, and built on the stellar efforts from Iowa Health in the United States, has simplified the questions patients or family members should be able to answer before leaving their care providers (www.npsf.org laskme3). The 3 key questions are: What is my main problem? What do I need to do? Why is it important for me to do this? The devil in the details is that the patient must verbally relate this information back to the provider before leaving a step that ensures the patient's comprehension of the issues.

The second common factor associated with preventable adverse events identified by Bartlett and colleagues is poor clinical management. This factor, unfortunately, is not simple to fix. The reliability of care improves when care is standardized and developed to manage the condition rather than when it is fashioned and limited according to payment methods or organizational structure. Health care in the United States has been abysmal in separating financial reimbursement from the care processes, but health care systems in other countries have fared only marginally better. Although,

Allan Frankel is a faculty member with the Institute for Healthcare Improvement, Cambridge, Mass., and the Division of General Medicine, Brigham and Women's Hospital, Boston, Mass. 
in the United States, misaligned payment incentive is the major issue, in Canada and the United Kingdom, physician myopia favouring practice autonomy over practice standardization continues to undermine the reliability and cost savings that accrue from the application of human factors to care delivery. Simplification, performance measurement and continuous refinement are at least understood today, but not well applied yet, in health care. There are some who are ahead of the curve: at Intermountain Health in the state of Utah, for example, standardization of practice has led to healthier patients at substantially lower costs than in the rest of the United States. ${ }^{7}$ France leads the European Union nations in value for money spent on the delivery of care. In England, the National Health System fares almost as well. The costs in both countries are a fraction of the US costs. ${ }^{8}$

Health care delivery is complicated, and health care providers universally try to do their best under difficult conditions. The study by Bartlett and colleagues identifies, once again, the extent to which the process is fraught with risk, and it adds to the literature by characterizing the increased risk in a subset of our patients. Some fixes seem simple, others wholly disruptive. But they are feasible where there is a will. Let's hope this study strengthens the will.

Competing interests: None declared.

\section{REFERENCES}

I. Bartlett $\mathrm{G}$, Blais R, Tamblyn R, et al. Impact of patient communication problems on the risk of preventable adverse events in acute care settings. CMAJ 2008; I78:1555-62.

2. Schwartzberg JG, VanGeest JB, Wang CC, editors. Understanding health literacy: implications for medicine and public health. Chicago: American Medical Association Press; 2005.

3. Iezzoni LI, O'Day BL, Killeen M, et al. Communicating about health care: observations from persons who are deaf or hard of hearing. Ann Intern Med 2004; I40:356-62.

4. Kutner M, Greenberg E, Jin Y, et al. The health literacy of America's adults: results from the 2003 National Assessment of Adult Literacy. Washington (DC): US Department of Education. National Center for Education Statistics; September 2006. Publication no. 2006-483. Available: http://nces.ed.gov/pubsearch/pubsinfo.asp ?pubid=2006483 (accessed 2008 Apr ig).

5. Griffin J, McKenna K, Tooth L. Discrepancy between older clients' ability to read and comprehend and the reading level of written educational materials used by occupational therapists. Am J Occup Ther 2006;60:70-80.

6. American Medical Association Foundation. Health literacy. Available: www .amafoundation.org/go/healthliteracy (accessed 2008 Apr I9).

7. Wennberg JE, Fisher ES, Sharp SM, et al. The care of patients with severe chronic illness: a report on the Medicare program by the Dartmouth Atlas Project. New Hampshire: The Trustees of Dartmouth College; 2005.

8. Freeman R. The politics of health in Europe. Manchester: Manchester University Press; 2000. p. 52-4.

Correspondence to: Dr. Allan Frankel, I5 Whitetail Lane, Sudbury

MA oI776 USA; Allan.frankel@lotusforum.com 